\title{
The value of an implicit self-associative measure specific to core beliefs of depression
}

Citation for published version (APA):

Lemmens, L. H. J. M., Roefs, A., Arntz, A., van Teeseling, H. C., Peeters, F. P. M. L., \& Huibers, M. J. H. (2014). The value of an implicit self-associative measure specific to core beliefs of depression. Journal of Behavior Therapy and Experimental Psychiatry, 45(1), 196-202.

https://doi.org/10.1016/j.jbtep.2013.10.006

Document status and date:

Published: 01/03/2014

DOI:

10.1016/j.jbtep.2013.10.006

Document Version:

Publisher's PDF, also known as Version of record

Document license:

Taverne

Please check the document version of this publication:

- A submitted manuscript is the version of the article upon submission and before peer-review. There can be important differences between the submitted version and the official published version of record.

People interested in the research are advised to contact the author for the final version of the publication, or visit the DOI to the publisher's website.

- The final author version and the galley proof are versions of the publication after peer review.

- The final published version features the final layout of the paper including the volume, issue and page numbers.

Link to publication

\footnotetext{
General rights rights.

- You may freely distribute the URL identifying the publication in the public portal. please follow below link for the End User Agreement:

www.umlib.nl/taverne-license

Take down policy

If you believe that this document breaches copyright please contact us at:

repository@maastrichtuniversity.nl

providing details and we will investigate your claim.
}

Copyright and moral rights for the publications made accessible in the public portal are retained by the authors and/or other copyright owners and it is a condition of accessing publications that users recognise and abide by the legal requirements associated with these

- Users may download and print one copy of any publication from the public portal for the purpose of private study or research.

- You may not further distribute the material or use it for any profit-making activity or commercial gain

If the publication is distributed under the terms of Article $25 \mathrm{fa}$ of the Dutch Copyright Act, indicated by the "Taverne" license above, 


\title{
The value of an implicit self-associative measure specific to core beliefs of depression
}

\author{
Lotte H.J.M. Lemmens $^{\mathrm{a}, *}$, Anne Roefs ${ }^{\mathrm{a}}$, Arnoud Arntz ${ }^{\mathrm{a}}$, Heleen C. van Teeseling ${ }^{\mathrm{b}}$, \\ Frenk Peeters ${ }^{c}$, Marcus J.H. Huibers ${ }^{\mathrm{a}, \mathrm{d}}$ \\ ${ }^{a}$ Department of Clinical Psychological Science, Faculty of Psychology and Neuroscience, Maastricht University, P.0. Box 616, 6200 MD Maastricht, \\ The Netherlands \\ ${ }^{\mathrm{b}}$ Department of Paediatric Psychology, Sector of Neuropsychology, University Medical Centre Utrecht, P.0. Box 85090, 3508 AB Utrecht, The Netherlands \\ ${ }^{\mathrm{c}}$ Department of Psychiatry and Neuropsychology, Maastricht University Medical Centre, P.O. Box 5800, 6202 AZ Maastricht, The Netherlands \\ ${ }^{\mathrm{d}}$ Department of Clinical Psychology, VU University Amsterdam, Van der Boechorststraat 1,1081 BT Amsterdam, The Netherlands
}

\section{A R T I C L E I N F O}

\section{Article history:}

Received 14 June 2012

Received in revised form

4 September 2013

Accepted 16 October 2013

\section{Keywords:}

Implicit measure of self-esteem

Sc-IAT

Explicit measure of self-esteem

Depression

Psychotherapy

\begin{abstract}
A B S T R A C T
Background and objectives: The present study examined differences in explicit and implicit measures of self-esteem between depressed patients and healthy controls using an indirect measurement procedure especially adapted to measure self-esteem aspects of core beliefs of depression. Furthermore, we examined whether our implicit and explicit self-associative measures were associated with each other and with depressive symptoms, and investigated the effect of a discrepancy between the implicit and explicit measure on depression.

Methods: Participants were 87 depressed patients and 30 healthy controls. The Self-Liking and SelfCompetence Scale was administered as a measure of explicit self-esteem. A depression-specific variant of the Single Category Implicit Association Test served as a measure of implicit self-esteem.

Results: Patients showed significantly lower levels of explicit self-esteem as compared to healthy controls. In spite of our adaptations, no differences were found on the implicit measure. The implicit measure of self-esteem was neither related to the explicit measure nor to depressive symptoms. Furthermore, although both the explicit measure of self-esteem and the difference score of the explicit and implicit measure were related to symptoms of depression, the relation between the explicit measure and depression was found to be significantly stronger.

Limitations: Results should be interpreted with caution because it is not clear yet to what extent these implicit measures really reflect self-esteem.

Conclusions: This study suggests that only the explicit measure of self-esteem - and not the implicit - is related to depression. Future research using well-designed measurement procedures for obtaining implicit and explicit measures could contribute to a better insight in the nature of these constructs.
\end{abstract}

(c) 2013 Elsevier Ltd. All rights reserved.

\section{Introduction}

According to cognitive theory, the self-concept is negatively biased in depressed patients (Beck, 1987; Greenwald \& Farnham, 2000). Depressed patients tend to think more negatively about themselves, and report lower self-esteem than healthy controls do (Ingram, Miranda, \& Segal, 1998). This reduces subjective wellbeing. Cognitive theory states that individuals at risk for depression developed latent negative schemas about the self, the world and the future. More specifically, depressogenic core beliefs about the

\footnotetext{
* Corresponding author. Tel.: +31 (0)43 3881874; fax: +31 (0)43 3884155.

E-mail address: Lotte.Lemmens@maastrichtuniversity.nl (L.H.J.M. Lemmens).
}

self are categorized as beliefs related to unlovability, helplessness, and incompetence (Beck, Rush, Shaw, \& Emery, 1979). These schemas come to the surface in periods of stress and influence the responses to stressful life circumstances (Beck, 1987; Clark, Beck, \& Alford, 1999). However, the relation between negative core beliefs about the self and depressive symptoms has not been elucidated yet, and the current state of the art in this field is mainly based on research using explicit measures. Explicit measures of self-esteem reflect rational and conscious processing of selfrelevant stimuli. However, in the past decades, an increasing number of researchers have acknowledged that self-schemata may also be reflected by more automatic and intuitive processing of affective experiences (Clark et al., 1999; Haaga, Dyck, \& Ernst, 1991; Steinberg, Karpinski, \& Alloy, 2007). To the extent that implicit 
measures reflect uncontrollable, unaware and fast mechanisms, they could reveal insights beyond those of explicit measures. Furthermore, the use of explicit measures has methodological disadvantages such as reliance on introspection capacities and socially desirable answering tendencies, which might bias the outcomes. Implicit measures partly overcome these drawbacks because they do not rely on introspection and participants only have limited possibilities to respond in a socially desirable way (De Houwer, 2006; Glashouwer \& de Jong, 2008; Steffens, 2004).

As a result, the interest for the use of implicit measures in research on vulnerability to depression has grown, and various measurement procedures have been developed to obtain implicit measures of self-esteem (e.g. the Word Completion Task (WCT; Bosson, Swann, \& Pennebaker, 2000); the Name Letter Task (NLT; Nuttin, 1985); and the Go/No-Go Association Task (GNAT; Nosek \& Banaji, 2001)), with the Implicit Association Task (IAT: Greenwald \& Farnham, 2000) being the most frequently used in this field. As recommended by De Houwer, Teige-Mocigemba, Spruyt, and Moors (2009), it is useful to distinguish between indirect measurement procedures and measures. A measurement procedure is the specific methodology; the set of guidelines followed that lead to an outcome. A measure is defined as 'a measurement outcome that is causally produced by the to-be-measured attribute in the absence of certain goals, awareness, substantial cognitive resources, or substantial time' (p.350). In this article, we will use the term 'implicit measure' to refer to the outcome of the Single Category Implicit Association Test (Sc-IAT: Karpinski \& Steinman, 2006) specific to measure core beliefs of depression.

The introduction of implicit measures in the field of self-esteem initially led to a debate about which measure reflected a person's 'true' attitude (e.g. Fazio \& Olson, 2003). However, dual-process models (Epstein, 1994) showed that both implicit and explicit cognitive processes influence depressive reactions to stressful life events, but do so in different ways (e.g. Beevers, 2005; Haeffel et al., 2007). The current thinking therefore treats implicit and explicit measures as complementary rather than as competitors, and consensus has been reached about the fact that using both measures can contribute to a deeper understanding of self-esteem (De Houwer, 2006; De Houwer et al., 2009; De Raedt, Schacht, Franck, \& De Houwer, 2006; Karpinski \& Steinman, 2006; Roefs et al., 2011).

Even though interest has grown, research with implicit measures of self-esteem is relatively scarce. Remarkably, the results of the few studies that actually obtained implicit measures of selfesteem in the context of depression often contradict results obtained by explicit measures. Although it is consistently shown in research using explicit measures that depressed patients have a more negative self-image than healthy controls (e.g. Hollon, Kendall, \& Lumry, 1986; Silverman, Silverman, \& Eardley, 1984; Xi, Zhang, \& Li, 2007), up until now only two studies found evidence for decreased self-esteem on implicit measures in currently depressed patients (Glashouwer \& de Jong, 2010; Risch et al., 2010). The vast majority of studies that obtained implicit measures of selfdepressive associations in depressed patients found evidence for positive self-esteem in both healthy individuals and in depressed patients, regardless of the measurement procedure that was used (De Raedt et al., 2006; Franck, De Raedt, \& De Houwer, 2007; Franck, De Raedt, \& De Houwer, 2008; Franck, De Raedt, Dereu, \& van den Abbeele, 2007; Gemar, Segal, Sagrati, \& Kennedy, 2001; Valiente et al., 2011).

The observation that implicit and explicit measures consistently show diverging results is at least unexpected, and might suggest that they reflect different constructs. Several research groups explain these findings as an indication that not the absolute levels of implicit and explicit measures of self-esteem separately, but the discrepancy between them (either expressed as an interaction or difference score of the explicit and implicit measure) plays a crucial role in the cause and maintenance of depression, because it represents deficiencies in the integration of self-representations, which is related to internalizing problems (e.g. Bosson, Brown, Zeigler-Hill, \& Swann, 2003; Creemers, Scholte, Engels, Prinstein, \& Wiers, 2012; Franck, De Raedt, \& De Houwer, 2007; Schröder-Abé, Rudolph, \& Schütz, 2007). Moreover, because these findings are consistent but not in line with cognitive theory of depression, one could even argue that the theory needs to be adapted. However, because measurement procedures for obtaining implicit measures are relatively young and the best way to obtain an implicit measure of self-esteem is still unclear (Garety \& Freeman, 1999; McKay, Langdon, \& Coltheart, 2007), these conclusions might be premature and it might be too soon to question the validity of cognitive theory. Another, in our view more plausible, reason for these contradictory findings between results obtained by implicit and explicit measures might be the lack of specificity of the instruments that have been used. Further research would benefit from careful design of measurement procedures to obtain implicit measures, paying attention to factors such as the exact choice of paradigm, and the selection of stimuli.

With regard to the selection of stimuli, it would make sense to design a task that is more specifically designed to measure depressogenic core beliefs related to self-esteem: unlovability, helplessness, and incompetence (Beck et al., 1979). This might lead to larger contrasts between the groups because specific beliefs are only expected to be revealed in depressed patients and not in healthy controls. Several studies have already used target words related to depression (e.g., Franck, De Raedt, Dereu, et al., 2007; Glashouwer \& de Jong, 2010; Risch et al., 2010), and found results that were contradictory to each other and (in some cases) to cognitive theory. It has to be noted that these studies chose a different focus in the selection of stimuli. Glashouwer and de Jong (2010) and Risch et al. (2010) used words that were related to the general concept of depression (for example fragile, pessimistic, negative vs. active, cheerful, lively), whereas Franck, De Raedt, Dereu, et al. (2007) specifically focused on 'worthlessness', one of the core concepts of depression (e.g., capable, valuable vs. inferior, worthless).

Furthermore, these studies (Franck, De Raedt, Dereu, et al., 2007; Glashouwer \& de Jong, 2010; Risch et al., 2010) used an original IAT paradigm. A drawback of the original IAT is that it can only provide information regarding the relative strength of various associations ('me' compared to 'other'). Because the IAT opposes the 'self category with 'other', the strength of the association between self and attributes is partially biased by the strength of the association between the category 'other' and attributes. The IAT is therefore unable to indicate the strength of the evaluation of 'me' or 'other' separately. To avoid this potential contamination, and measure the associations with the self in isolation, a variant of the IAT: the single category IAT (Sc-IAT: Karpinski \& Steinman, 2006) can be used. Because the Sc-IAT has no reference group 'other', it is able to measure the absolute strength of associations between the target category (i.e., 'self in our study) and the attributes.

The central goal of the present study was therefore to optimize our implicit measure by not only adapting the measurement procedure to reflect the depressogenic core beliefs, but also by using a Sc-IAT paradigm. To our knowledge, this is the first study using a single category measurement procedure exclusively adapted to this target group. By comparing scores on implicit and explicit measures of self-esteem of depressed patients and healthy controls, the hypothesis was tested that depressed patients, who were about to start psychotherapy, would show more negative self-associations than would healthy control participants. Furthermore, we examined whether our implicit and explicit self-associative measures 
were associated with each other and with depressive symptoms. In addition, even though the discrepancy hypothesis arose as a posthoc explanation, it has now been used as a theoretical explanation of depression by several research groups (e.g., Creemers et al., 2012; Franck, De Raedt, \& De Houwer, 2007, Franck, De Raedt, Dereu, et al., 2007), and warrants further examination. We therefore investigated the effects of the discrepancy between scores on the implicit and explicit measure of self-esteem on depression, using two different methods to assess discrepancy that are used in current literature (i.e., the interaction and the difference score of the explicit and the implicit measure).

\section{Method}

\subsection{Participants}

The clinical sample consisted of 87 depressed patients $(69 \% \mathrm{fe}-$ male). They were between 18 and 62 years old $(M=42.30$, $S D=10.87$ ) and $41.4 \%$ was educated on medium level (low: $25.3 \%$, high: 26.4\%). Their average score on the Beck Depression InventoryII (BDI-II; Beck, Steer, \& Brown, 1996) was 27.24 (SD = 9.04). The healthy control sample consisted of 30 participants (67\% female), who ranged in age from 18 to 65 years $(M=44.53, S D=15.13)$ and had BDI-II scores ranging from 0 to $9(M=3.17, S D=2.67)$. The majority of the controls (56.7\%) were educated on medium level (low: 10.0\%, high: 26.7\%). No significant differences were found between groups on age $(t(40)=0.75, p=.46)$, gender $\left(\chi^{2}(1\right.$, $N=117)=0.06, p=.82)$, and level of education $(F(1,109)=0.51$, $p=.48)$.

\subsection{Recruitment and procedure}

Patients were recruited as part of a large ongoing randomized controlled trial aimed at the effectiveness, mechanisms of change and relapse prevention of Cognitive Therapy (CT) and Interpersonal Psychotherapy (IPT) for depression. The study is registered at the Netherlands Trial Register, part of the Dutch Cochrane Centre (ISRCTN67561918). The main design of the study is fully described elsewhere (Lemmens et al., 2011). Patients were adult outpatients (18-65 years) referred to the mood disorder unit of the Maastricht Community Mental Health Centre with a primary diagnosis of Major Depressive Disorder (MDD) confirmed by the Structured Clinical Interview for DSM-IV Axis I disorders (SCID-I; First, Spitzer, Gibbon \& Williams, 1997). Further inclusion criteria were: internet access, an e-mail address, and sufficient knowledge of the Dutch language. Exclusion criteria were: bipolar or chronic ( $>5$ years) depression, current use of antidepressant medication, drugs- and alcohol abuse/dependence, and mental retardation (IQ $<80$ ). Healthy participants were recruited in the general population. After ruling out the presence of depressive symptoms (BDI-II $\leq 10)$ and other psychopathology in a telephone screening, participants were invited.

After informed consent was given, the assessment started with a brief verbal description of the procedure. All participants were told that they were going to perform a word-sorting task that required concentration, and that they subsequently would answer several questionnaires about aspects of psychological functioning. Healthy participants were debriefed afterwards. For depressed patients, debriefing took place after completing the total study.

\subsection{Measures}

\subsubsection{Beck Depression Inventory-II}

The Beck Depression Inventory-II (BDI-II; Beck et al., 1996; Dutch translation by Van der Does, 2002), is a 21-item self-report questionnaire used to measure the severity of depression. Each item is rated on a 4-point Likert-scale ranging from 0 to 4 . Higher scores indicate higher levels of depression. The questionnaire has strong psychometric properties as a screening measure for depression (Beck et al., 1996; Van der Does, 2002).

\subsubsection{Depression specific Single Category Implicit Association Test}

The Single Category Implicit Association Test (Sc-IAT; Karpinski \& Steinman, 2006) is an adaptation of the original IAT (Greenwald \& Farnham, 2000; Greenwald, McGhee, \& Schwartz, 1998) and was used to obtain an implicit measure of specific core beliefs of depression exclusively related to the concept of the self. Instruments such as the Sc-IAT measure associations between the self and certain attributes, which are assumed to be an indication of self-esteem. The task consisted of 3 blocks of trials and started with a practice block. In the practice block, 12 positive and 12 negative words (attributes) were presented, and the task for participants was to categorize these attributes as such by pressing the appropriate key (left or right shift key marked with a blue sticker) as quickly as possible without making too many errors. After the practice block, there were two test blocks. In the test blocks, a third word category was added to the positive and negative attributes: stimuli representing the self (self-stimuli). In one test block, selfstimuli shared a response key with positive attributes, while the other key needed to be pressed for negative attributes ('pos + me' block). In the other test block, the key assignment for self-stimuli was switched. They now shared a response key with the negative attributes and the other key needed to be pressed for positive words ('neg + me' block). Each test block consisted of 12 practice trials ( 7 attributes and 5 self-stimuli) immediately followed by 72 test trials: 30 self-stimuli and 42 attributes. The 42 attributes consisted of 30 negative and 12 positive trials for the 'pos + me' blocks and vice versa for the 'neg + me' blocks. Each block was preceded by a set of instructions concerning the dimension(s) of the categorization task and the appropriate key response. The assignment of positive and negative attributes to the right and left key and the order of test blocks were balanced over participants. Because the Sc-IAT has only three categories, it was not possible to have both an equal number of attributes per category (pos/neg) and an equal number of stimuli per response key. However, the Sc-IAT score was computed by comparing the two phases (me-pos and me-neg) and in both of these phases the distribution over response buttons was equal for all participants. During the task, attributes (pos/neg) and self-stimuli appeared on the computer screen one by one, and in a random order unique for each participant.

The rationale behind the Sc-IAT is that the response time is expected to be faster when two compatible concepts are mapped together on the same key, as compared to when two less compatible concepts are mapped together. For example, for people with a positive self-esteem, when the categories 'positive' and 'me' are mapped onto the same key, the response time is predicted to be faster than for the reversed combination ('negative' and 'me') (Karpinski \& Steinman, 2006).

A total of 18 different stimuli were used; 6 positive and 6 negative attributes and 6 self-related target stimuli. The Dutch words for 'I' (ik), 'me' (me), 'self (zelf), 'my' (mij), 'own' (eigen), and 'mine' (mijn) served as self-related target stimuli. As has been noted earlier, all attributes referred to one of three main cognitive themes in depression according to Beck (1987). Negative words that represented the concept of unlovability were the Dutch words for 'rejected' (afgewezen) and 'harmful' (schadelijk). The Dutch words for 'worthless' (waardeloos) and 'redundant' (overbodig) were selected to represent the core belief worthlessness and the Dutch translation of 'helpless' (hulpeloos) and 'vulnerable' (kwetsbaar) served as a representation of the concept of 
helplessness. The positive words were chosen as counterparts of the negative words. These were the Dutch words for 'beloved' (geliefd) and 'pleasant/nice' (aangenaam) for unlovability; 'powerful' (krachtig), and 'successful' (geslaagd) for helplessness, and 'perfect' (perfect), and 'valuable' (waardevol) for worthlessness. All attribute stimuli were derived from the list of Hermans and De Houwer (1994) and were matched on subjective familiarity by ratings of 25 University employees. The final positive and negative word sets were found to be statistically equivalent with regard to familiarity $(t(10)=1.24, p=.24)$ but showed a small difference with regard to worth length $(t(10)=4.03, p<.01)$. Because in the Dutch language negative words are often composed by the positive word plus a negation (e.g. the counterpart for the positive word 'waarde-vol' is 'waarde-loos'), negative words $(M=9.33, S D=.52)$ consisted on average of more letters than did the positive words $(M=7.83$, $S D=.75)$. Stimulus presentation was controlled by Inquisit Millisecond Software (v. 2.0). The background colour of the computer screen was white and all stimulus words were individually displayed in the centre of the screen in black ARIAL font 48 letters. During the task the target-labels ('positive', 'negative' and 'me') were displayed at the top of the screen.

\subsubsection{Self-Liking and Self-Competence Scale Revised}

The Self-Liking and Self-Competence Scale Revised (SLCS-R, Tafarodi \& Swann, 2001; Dutch Translation by Vandromme, Hermans, Spruyt \& Eelen, 2007) was used as an explicit measure of self-esteem. This 16-item self-report questionnaire is developed to measure Self-Liking and Self-Competence, two important dimensions of self-esteem. The subscale Self-Liking measures the subjective evaluation of personal worth. The subscale SelfCompetence measures the sense of one's capability of successful intentional goal pursuit, derived from multiple experiences (Tafarodi \& Swann, 2001). The SLSC-R contains eight items for each of the two subscales (e.g. Self-Competence; 'I am highly effective at the things I do' and Self-Liking: 'I tend to devalue myself'). Items are rated on a 5-point Likert-scale and subscale scores can range from 8 to 40 , with higher scores indicating higher Self-Competence or higher Self-Liking. Following Hermans et al. (2008) we also calculated a total score by adding up the scores of the two subscales (range 16-80). ${ }^{1}$ Psychometric properties of the Dutch version of the SLCS-R have been described as good (Vandromme, Hermans, Spruyt, \& Eelen, 2007).

\subsection{Statistical analysis}

Only cases with complete data were entered in the analyses. Originally, 106 depressed patients and 34 healthy controls were tested. 19 depressed participants had missing data and were therefore excluded from analyses. Furthermore, four controls appeared to have a BDI-II score higher than 10 , which might indicate mild depressive symptoms, and were therefore also excluded. In total, data of 87 depressed patients and 30 healthy controls were used in the analyses. The Sc-IAT effect was calculated using the improved D600-score algorithm (Greenwald, Nosek, \& Banaji, 2003), with higher scores indicating a tendency to associate the self more strongly with positive words than with negative words. Independent samples $t$-tests were used to examine differences between patients and controls on the SLSC-R total- and subscale scores, and the Sc-IAT. Pearson's correlations were calculated to investigate the relationship among the implicit and explicit

\footnotetext{
${ }^{1}$ Both SLSC-R subscales and the total score were reliable in terms of internal consistency; that is, Cronbach's $\alpha$ 's were good ( $\alpha$ 's between .87 and .94 ). Furthermore, the two subscales were highly correlated $(r(117)=0.77, p<.01)$.
}

Table 1

Mean (SD) scores and differences on the explicit and implicit measures of selfesteem between depressed patients and healthy controls.

\begin{tabular}{lrrl}
\hline & $\begin{array}{l}\text { Patients } \\
(n=87)\end{array}$ & $\begin{array}{l}\text { Controls } \\
(n=30)\end{array}$ & $\begin{array}{l}\text { Independent } \\
\text { samples T-test }\end{array}$ \\
\hline SLSC-R & & & \\
$\quad$ Total score & $39.69(8.92)$ & $59.97(7.88)$ & $t=-11.05, p=<0.001$ \\
Self-Liking & $18.79(5.20)$ & $31.53(4.85)$ & $t=-11.77, p=<0.001$ \\
Self-Competence & $20.90(4.74)$ & $28.43(3.87)$ & $t=-7.85, p=<0.001$ \\
Sc-IAT & $0.12(0.45)$ & $0.17(0.42)$ & $t=-0.56, p=.58$ \\
SLSC-R total - Sc-IAT* & $-39.57(8.90)$ & $-59.79(7.92)$ & $t=11.02, p=<0.001$ \\
\hline
\end{tabular}

Note: BDI-II = Beck Depression Inventory-Second Edition; SLSC-R = Self-Liking and Self-Competence Scale Revised; Sc-IAT = Single Category Implicit Association Test D600-score; * = Mean (SD) standardized difference score (z_SLSC-R total - z_ScIAT) $=0.39(1.21)$ and $-1.13(1.18)$ for patients and controls respectively $(t(115)=5.95, p<.01)$.

measure. To further examine the relationship between the explicit and implicit measure of self-esteem, their discrepancy, and depression, regression analysis was used. We started with a multiple hierarchical regression model with depression severity being the dependent variable and centered total scores on the implicit and explicit measure being potential predictors. In line with previous research by for example Franck, De Raedt, and De Houwer (2007) and Schröder-Abé et al. (2007), we examined main effects of both self-esteem measures (centered scores) on depressive symptoms in step 1 and checked for the effect of the discrepancy between both variables expressed as a centered interaction score (c_implicit * c_explicit) in step 2 using the procedure proposed by Aiken and West (1991).

Furthermore, we examined the discrepancy expressed as a difference score between implicit and explicit measures of selfesteem. Following studies by for example Creemers et al. (2012) and Kesting, Mehl, Rief, Lindenmeyer, and Lincoln (2011) we subtracted the standardized score on the explicit measure from the standardized score on the implicit measure (z_implicit - z_explicit), and examined the effect of this discrepancy score on depression in a separate regression analysis. ${ }^{2}$ In order to shed more light on the magnitude of the effect of this second method, the difference score model was compared with the main effect models obtained in step 1 of the hierarchical regression analysis.

\section{Results}

Table 1 shows the descriptive statistics of patients and controls and the differences between the groups on the self-associative measures. Analysis showed significant differences between patients and controls on the explicit measure of self-esteem: patients reported significantly lower scores as compared to healthy controls. On the implicit measure, the group as a whole (i.e., depressed patients and healthy controls) showed significantly stronger associations between positive attributes and self-related stimuli than between negative attributes and self-related stimuli $(t(116)=3.12$, $p<.01)$. No significant differences in Sc-IAT scores were found between the patients and healthy control participants. Furthermore, there was a significantly larger difference between implicit

\footnotetext{
${ }^{2}$ Because the difference score is derived from the variance related to both the implicit and explicit measure (z_implicit - z_explicit), it was statistically impossible to control for the main effects of scores obtained on the explicit and implicit measures of self-esteem. In short, including both the difference score and main scores in one model would eliminate the effect of the difference score from the equation. As a result, we would then be testing a main effects model that is identical to the model that was already tested in step 1 of the regression analysis.
} 
Table 2

Associations of the explicit and implicit measures of self-esteem and their interaction with depressive symptoms.

\begin{tabular}{llll}
\hline & BDI-II & & \\
\cline { 2 - 4 } & $B$ & SE & $\beta$ \\
\hline Step 1 & & 0.07 & $-0.70^{*}$ \\
SLSC-R & -0.75 & 2.00 & -0.02 \\
Sc-IAT & -0.49 & & 0.00 \\
Step 2 & & 0.17 & 0.00 \\
SLSC-R $\times$ Sc-IAT & -0.00 &
\end{tabular}

Note: All independent variables are centered; BDI-II = Beck Depression InventorySecond Edition; SLSC-R = Self-Liking and Self-Competence Scale Revised Total Score; Sc-IAT $=$ Single Category Implicit Association Test D600-score; $R^{2}=0.49$ in step $1(p=.01) ; \Delta R^{2}=0.49$ in step $2(p=.99) ;{ }^{*}=p<.001$.

and explicit measures of self-esteem in healthy controls than in patients. See Table 1 for relevant statistics.

No significant correlations were found between the total scores on the implicit and explicit measures $(r(117)=0.06, p=.54)$. Furthermore, correlation analyses for the two dimensions of the explicit measure separately showed similar results. In addition, there were no differences in correlational patterns between patients and controls. Results of the hierarchical regression analysis used to examine main effects of the self-esteem measures and their interaction on depression are displayed in Table $2 .{ }^{3}$ Results of step 1 indicate that lower scores on the explicit measure of self-esteem are associated with higher levels of depressive symptoms $(\beta=.70, t(114)=10.51, p<.001)$. No significant main effect was found of the implicit measure $(\beta=.02, t(114)=0.24, p=.81)$. The interaction term was not significant, meaning that the discrepancy between the explicit and implicit measure of self-esteem score expressed as an interaction between the two variables, did not relate to depressive symptoms.

With regard to the effects of the discrepancy score expressed as a difference between the standardized measures of implicit and explicit self-esteem, it was found that a larger discrepancy was significantly associated with symptoms of depression $(\beta=.47$, $t(114)=5.714, p<.001)$. In order to shed more light on the magnitude of this effect, the model was compared to the significant main effect model obtained in step 1 using the method of Steiger (1980). Analysis showed that the relation between the explicit measure of self-esteem and symptoms of depression was significantly stronger than the relation between discrepancy and depressive symptoms $(Z=-8.83, p<.01)$.

\section{Discussion}

\subsection{Main findings}

The objective of the current study was to examine whether there are differences in scores on implicit and explicit measures of self-esteem between depressed patients and healthy control participants. Furthermore, we examined whether our implicit and explicit self-associative measures and their discrepancy (expressed as an interaction and difference score) were associated with symptoms of depression. It was expected that depressed patients would show reduced scores on both the implicit and explicit measure of self-esteem as compared to healthy controls, and that larger discrepancies between the two measures would be related to more severe depressive symptoms.

\footnotetext{
${ }^{3}$ Analysis of the SLSC-R total score and both dimensions of the SLSC-R (SelfLiking and Self-Competence) separately showed similar results.
}

In line with prior research (e.g., Hollon et al., 1986; Silverman et al., 1984; Xi et al., 2007), expected differences were found on the explicit measure. However, in spite of our attempt to create larger contrasts between patients and controls by adapting our ScIAT specifically to measure depressive core beliefs, depressed patients did not score lower on this implicit measure of self-esteem than did healthy controls. These results resemble those of other studies that obtained implicit measures of self-esteem in depressed patients and healthy controls and also did not find differences (Creemers et al., 2012; De Raedt et al., 2006; Franck, De Raedt, \& De Houwer, 2007, Franck, De Raedt, Dereu, et al., 2007; Gemar et al., 2001) and those who compared scores on both self-associative measures within depressed patient and found reduced levels of explicit, but normal levels of implicit self-esteem (Kesting et al., 2011; Valiente et al., 2011). Our results are not in line however, with studies conducted by Risch et al. (2010) and Glashouwer and de Jong (2010) who did find differences on implicit self-associative measures between depressive patients and healthy controls. Furthermore, our finding that the score on the implicit measure of self-esteem was not directly associated with the score on the explicit measure and with depressive symptoms, whereas explicit self-esteem showed a significant inverse relation with depression, is in line with previous research (e.g., Creemers et al., 2012; Kesting et al., 2011; Vázquez, Diez-Alegría, Hernández-Lloreda, \& Moreno, 2008). The divergence between explicit and implicit measures was further underlined by a lack of correlations between these measures, which is also not uncommon in this field of research (see Roefs et al., 2011). In addition, even though we found that the discrepancy between the two self-associative measures expressed as an interaction was not associated with depression, the discrepancy expressed as a difference score was significantly related to depressive symptoms. These results show that interchangeably using two different methods to assess the same construct might not only lead to confusion because it is not clear what the concept exactly means and how it is measured, but also leads to diverging results. However, a closer look at the significant relation between the difference score and depression showed that this relation was significantly weaker than the relation between the explicit measure of self-esteem and depression. This might shed more light on the nature of the relation between discrepancy and depression; since the discrepancy score is a composition of the scores on the explicit and implicit measure, and no relation was found between the implicit measure and depression, one can argue that the effect of the discrepancy score is solely a result from variability in the explicit measure of self-esteem made statistically weaker by subtracting the implicit score - which increased error variance.

\subsection{Methodological considerations and recommendations}

Although consistent with the majority of previous research, our results contradict the cognitive theory of depression which states that the view of the self in general is negatively biased in depressed patients. It should be noted that findings from implicit measures often contradict the cognitive theory of the disorder (Roefs et al., 2011). The question that remains is whether this is reason to call for an adjustment of cognitive theory or that one should doubt the validity of the implicit measures. Because it is still not clear yet in what sense procedures such as the Sc-IAT can be considered implicit and valid indices of self-esteem (Buhrmester, Blanton, \& Swann, 2011; De Houwer, 2006), results obtained by implicit measures should be critically evaluated and interpreted with caution and before one can start thinking about changing or rejecting theory.

First of all, one could argue that our findings are the result of the specific paradigm we used. Because self-esteem is assumed to be a 
complex, multi-dimensional construct, it is possible that our implicit measure of self-esteem did not capture crucial aspects of the construct, which might have biased the results. However, previous research has consistently shown positive associations with the self in depressed patients, regardless of the measurement procedure that was used (e.g. Creemers et al., 2012; De Raedt et al., 2006). Therefore, it seems unlikely that the results that we obtained are due to the specific measurement procedure that was used to obtain an implicit measure of self-esteem, especially considering that we adapted the paradigm as much as possible to reflect depressive core beliefs.

Second, the lack of a direct comparison between our measure and another existing implicit measure of self-esteem might limit the possibilities to determine if our adaptations provide an advantage over existing measures. The problem with this however, is that in the field of implicit measures there is no such thing as a gold standard yet, which makes the exact choice of paradigm to compare with arguable (Roefs et al., 2011). Furthermore, adding a second implicit measure within one sample would also create extra problems such as order- and learning effects. We therefore think that, given the current status of the field, face value comparisons of design and methodology across studies and populations is a valid option to compare results.

Third, it is generally agreed upon that the (Sc-)IAT effect is largely determined by the category labels that have been chosen (De Houwer, 2001; Fazio \& Olson, 2003). Category labels are considered critical for the interpretation of stimulus items and thereby influence the implicit measure. One could therefore argue that the labels that were used in the current study ("positive' vs. 'negative') could have influenced the outcome, and that changing these category labels (for example into 'depressed' and 'elated' as in the study by Glashouwer \& de Jong, 2010) could lead to different results. However, we think it is unlikely that this has driven the effect. First of all because various other studies using different category labels were also not able to show reduced levels of implicit self-esteem in depressed patients (e.g., Franck et al., 2007 studies). And second, because Risch et al. (2010) used similar labels and actually did find differences between patients and controls.

Fourth, the fact that Glashouwer and de Jong (2010) assessed a sample that was 25.5 times larger than ours (2981 vs. 117) and found hypothesized results, might indicate that differences in implicit measures of self-esteem between patients and controls do exist, but that we were not able to reveal these differences because of insufficient power. However, we think that it is improbable that this has driven our effects, since our study has $98 \%$ power to detect a similar effect size ( $d=.86$ at two-tailed $\alpha=.05$ ) as Glashouwer and colleagues.

More likely is the explanation however, that these differences are due to the choice of target words. It is remarkable that the two studies that were able to demonstrate lower levels on implicit selfassociative measures (Glashouwer \& de Jong, 2010; Risch et al., 2010) used target words that reflected more general automatic self-associations instead of specific depressogenic core beliefs related to self-esteem. This might even indicate that perhaps not self-esteem but other self-relevant attributes are essential in implicit processes in depression. It is therefore important to examine whether patients who implicitly associate the self with for example pessimism, sadness, lack of motivation and passiveness, are at larger risk for developing depression, or whether those who are depressed develop implicit self-depressive associations. Another important question for future research is whether these selfassociations are of importance in the maintenance or relapse of depression.

\section{Conclusions}

In spite of the fact that our results do not fit with the dominant cognitive theories of depression, and despite a lack of clarity regarding the validity and implicit nature of the measurement outcome, the fact that the majority of studies failed to detect a depression specific effect involving implicit measures of selfesteem calls for interpretation. Perhaps most importantly, fundamental research on the validity and implicit character of these measures should progress, before firm conclusions can be drawn from implicit measures obtained in the domain of depression and self-esteem. Future research should focus on a further refinement of measurement procedures to obtain implicit measures. It is important to identify and select the best paradigm for the research question (De Houwer et al., 2009) by carefully evaluating whether a relative or absolute measure of associations is required, what target words fit the psychosocial attributes that are being studied best, and to what sense expected effects are thought to be implicit (Roefs et al., 2011). Only then can implicit measures prove to be a true and valuable addition to explicit measures, which have their own wellknown limitations such as a reliance on introspection and sensitivity to self-presentational concerns.

\section{Funding}

This research is funded by the Research Institute of Experimental Psychopathology (EPP) and the Academic Community Mental Health Centre (RIAGG) in Maastricht.

\section{Specific author contributions}

AR programmed the Sc-IAT paradigm. LL and HvT carried out recruitment and data-collection. LL undertook the statistical analyses and drafted the manuscript in close collaboration with AR. All authors participated in the design of the study, contributed to the writing of the manuscript and have approved of the final manuscript.

\section{Conflict of interest}

The authors declare that they have no competing interests.

\section{Acknowledgements}

We wish to thank Annie Hendriks and Annie Raven for their assistance during the study. Furthermore, we thank Katrijn Houben for her assistance in analysing the implicit measure and Rosanne Janssen for developing the infrastructure for the online datacollection.

\section{References}

Aiken, L. S., \& West, S. G. (1991). Multiple regression: Testing and interpreting interactions. Newbury Park, London: Sage.

Beck, A. T. (1987). Cognitive models of depression. Journal of Cognitive Psychotherapy: An International Quarterly, 2, 5-37.

Beck, A. T., Rush, A. J., Shaw, B. F., \& Emery, G. (1979). Cognitive therapy of depression. New York: Guilford Press.

Beck, A. T., Steer, R., \& Brown, G. K. (1996). Beck Depression Inventory II: Manual. Boston: Hartcourt Brace.

Beevers, C. G. (2005). Cognitive vulnerability to depression: a dual process model. Clinical Psychology Review, 25(7), 975-1002.

Bosson, J. K., Brown, R. P., Zeigler-Hill, V., \& Swann, W. B. (2003). Self-enhancement tendencies among people with high explicit self-esteem: the moderating role of implicit self-esteem. Self and Identity, 2, 169-187.

Bosson, J. K., Swann, W. B., Jr., \& Pennebaker, J. W. (2000). Stalking the perfect measure of implicit self-esteem: the blind men and the elephant revisited? Journal of Personality and Social Psychology, 79(4), 631-643. 
Buhrmester, M. D., Blanton, H., \& Swann, W. B., Jr. (2011). Implicit self-esteem: nature, measurement, and a new way forward. Journal of Personality and Social Psychology, 100(2), 365-385.

Clark, D. A., Beck, A. T., \& Alford, B. A. (1999). Scientific foundations of cognitive theory and therapy of depression. New York: John Wiley and Sons.

Creemers, D. H. M., Scholte, R. H. J., Engels, R. C. M. E., Prinstein, M. J., \& Wiers, R. W. (2012). Implicit and explicit self-esteem as concurrent predictors of suicidal ideation, depressive symptoms, and loneliness. Journal of Behavior Therapy and Experimental Psychiatry, 43(1), 638-646.

De Houwer, J. (2001). A structural and process analysis of the implicit association test. Journal of Experimental Social Psychology, 37(6), 443-451.

De Houwer, J. (2006). What are implicit measures and why are we using them? In R. W. Wiers, \& A. W. Stacy (Eds.), The handbook of implicit cognition and addiction (pp. 11-28) Thousand Oaks, CA: Sage Publishers.

De Houwer, J., Teige-Mocigemba, S., Spruyt, A., \& Moors, A. (2009). Implicit measures: a normative analysis and review. Psychological Bulletin, 135(3), 347-368.

De Raedt, R., Schacht, R., Franck, E., \& De Houwer, J. (2006). Self-esteem and depression revisited: implicit positive self-esteem in depressed patients? Behaviour Research and Therapy, 44, 1017-1028.

Epstein, S. (1994). Integration of the cognitive and the psychodynamic unconscious. American Psychologist, 49(8), 709-724.

Fazio, R. H., \& Olson, M. A. (2003). Implicit measures in social cognition research: their meaning and use. Annual Review of Psychology, 54, 297-327.

First, M. B., Spitzer, R. L., Gibbon, M., \& Williams, J. B. W. (1997). Structured Clinical Interview for DSM-IV Axis I disorders (SCID-I). New York: Biometrics Research Department New York State Psychiatric Institute.

Franck, E., De Raedt, R., \& De Houwer, J. (2007). Implicit but not explicit self-esteem predicts future depressive symptomatology. Behaviour Research and Therapy, 45(10), 2448-2455.

Franck, E., De Raedt, R., \& De Houwer, J. (2008). Activation of latent self-schemas as a cognitive vulnerability factor for depression: the potential role of implicit selfesteem. Cognition E Emotion, 22(8), 1588-1599.

Franck, E., De Raedt, R., Dereu, M., \& van den Abbeele, D. (2007). Implicit and explicit self-esteem in currently depressed individuals with and without suicidal ideation. Journal of Behavior Therapy and Experimental Psychiatry, 38, 75-85.

Garety, P. A., \& Freeman, D. (1999). Cognitive approaches to delusions: a critical review of theories and evidence. British Journal of Clinical Psychology, 38(2), $113-154$.

Gemar, M. C., Segal, Z. V., Sagrati, S., \& Kennedy, S. J. (2001). Mood-induced changes on the Implicit Association Test in recovered depressed patients. Journal of Abnormal Psychology, 110(2), 282-289.

Glashouwer, K. A., \& de Jong, P. J. (2008). Impliciete persoonlijkheidstrekken en psychopathologie: Achtergrond, huidige inzichten en perspectieven. Gedragstherapie, 41(2), 121-134.

Glashouwer, K. A., \& de Jong, P. J. (2010). Disorder-specific automatic selfassociations in depression and anxiety: results of The Netherlands Study of Depression and Anxiety. Psychological Medicine, 40(07), 1101-1111.

Greenwald, A. G., \& Farnham, S. D. (2000). Using the Implicit Association Test to measure self-esteem and self-concept. Journal of Personality and Social Psychology, 79(6), 1022-1038.

Greenwald, A. G., McGhee, D. E., \& Schwartz, J. L. K. (1998). Measuring individual differences in implicit cognition: the Implicit Association Test. Journal of Personality and Social Psychology, 74, 1464-1480.

Greenwald, A. G., Nosek, B. A., \& Banaji, M. R. (2003). Understanding and using the Implicit Association Test: I. An improved scoring algorithm. Journal of Personality and Social Psychology, 85(2), 197-216.

Haaga, D. A., Dyck, M. J., \& Ernst, D. (1991). Empirical status of cognitive theory of depression. Psychological Bulletin, 110(2), 215-236.

Haeffel, G. J., Abramson, L. Y., Brazy, P. C., Shah, J. Y., Teachman, B. A., \& Nosek, B. A. (2007). Explicit and implicit cognition: a preliminary test of a dual-process theory of cognitive vulnerability to depression. Behaviour Research and Therapy, 45(6), 1155-1167.
Hermans, D., \& De Houwer, J. (1994). Affective and subjective familiarity ratings of 740 dutch words. Psychologica Belgica, 34, 115-139.

Hermans, D., Vandromme, H., Debeer, E., Raes, F., Demyttenaere, K., Brunfaut, E. et al. (2008). Overgeneral autobiographical memory predicts diagnostic status in depression. Behaviour Research and Therapy, 46(5), 668-677.

Hollon, S. D., Kendall, P. C., \& Lumry, A. (1986). Specificity of depressotypic cognitions in clinical depression. Journal of Abnormal Psychology, 95(1), 52-59.

Ingram, R. E., Miranda, J., \& Segal, Z. V. (1998). Cognitive vulnerability to depression. New York: Guilford Press.

Karpinski, A., \& Steinman, R. B. (2006). The single category Implicit Association Test as a measure of implicit social cognition. Journal of Personality and Social Psychology, 91, 16-32.

Kesting, M.-L., Mehl, S., Rief, W., Lindenmeyer, J., \& Lincoln, T. M. (2011). When paranoia fails to enhance self-esteem: explicit and implicit self-esteem and its discrepancy in patients with persecutory delusions compared to depressed and healthy controls. Psychiatry Research, 186(2-3), 197-202.

Lemmens, L. H. J. M., Arntz, A., Peeters, F. P. M. L., Hollon, S. D., Roefs, A., \& Huibers, M. J. H. (2011). Effectiveness, relapse prevention and mechanisms of change of cognitive therapy vs. interpersonal therapy for depression: study protocol for a randomised controlled trial. Trials, 12(1), 150-162.

McKay, R., Langdon, R., \& Coltheart, M. (2007). The defensive function of persecutory delusions: an investigation using the Implicit Association Test. Cognitive Neuropsychiatry, 12(1), 1-24.

Nosek, B. A., \& Banaji, M. R. (2001). The Go/No-Go Association Task. Social Cognition, 19(6), 625-666.

Nuttin, J. M. (1985). Narcissism beyond Gestalt and awareness: the name letter effect. European Journal of Social Psychology, 15(3), 353-361.

Risch, A. K., Buba, A., Birk, U., Morina, N., Steffens, M. C., \& Stangier, U. (2010). Implicit self-esteem in recurrently depressed patients. Journal of Behavior Therapy and Experimental Psychiatry, 41, 199-206.

Roefs, A., Huijding, J., Smulders, F. T. Y., MacLeod, C. M., de Jong, P. J., Wiers, R. W. et al. (2011). Implicit measures of association in psychopathology research. Psychological Bulletin, 137(1), 149-193.

Schröder-Abé, M., Rudolph, A., \& Schütz, A. (2007). High implicit self-esteem is not necessarily advantageous: discrepancies between explicit and implicit selfesteem and their relationship with anger expression and psychological health. European Journal of Personality, 21, 319-339.

Silverman, J. S., Silverman, J. A., \& Eardley, D. A. (1984). Do maladaptive attitudes cause depression? Archives of General Psychiatry, 41, 28-30.

Steffens, M. C. (2004). Is the Implicit Association Test immune to faking? Experimental Psychology, 51, 165-179.

Steiger, J. H. (1980). Tests for comparing elements of a correlation matrix. Psychological Bulletin, 87(2), 245-251.

Steinberg, J. A., Karpinski, A., \& Alloy, L. B. (2007). The exploration of implicit aspects of self-esteem in vulnerability - stress models of depression. Self and Identity, 6(2-3), 101-117.

Tafarodi, R. W., \& Swann, W. B. (2001). Two-dimensional self-esteem: theory and measurement. Personality and Individual Differences, 31(5), 653-673.

Valiente, C., Cantero, D., VÃzquez, C., Sanchez, Ã., Provencio, M., \& Espinosa, R. (2011). Implicit and explicit self-esteem discrepancies in paranoia and depression. Journal of Abnormal Psychology, 120(3), 691-699.

Van der Does, A. J. W. (2002). De Nederlandse versie van de Beck Depression Inventory - second edition (BDI-II-NL): Handleiding.

Vandromme, H., Hermans, D., Spruyt, A., \& Eelen, P. (2007). Dutch translation of the Self-Liking/Self-Competence Scale - revised: a confirmatory factor analysis of the two-factor structure. Personality and Individual Differences, 42(1), 157-167.

Vázquez, C., Diez-Alegría, C., Hernández-Lloreda, M. J., \& Moreno, M. N. (2008) Implicit and explicit self-schema in active deluded, remitted deluded, and depressed patients. Journal of Behavior Therapy and Experimental Psychiatry, 39(4), 587-599.

Xi, M.-J., Zhang, Y.-J., \& Li, Y.-X. (2007). Implicit self-esteem level and stability of depressive patients. Chinese Mental Health Journal, 21(11), 756-758. 